\title{
Leptin and thyroxine during sexual development in male monkeys: effect of neonatal gonadotropin-releasing hormone antagonist treatment and delayed puberty on the developmental pattern of leptin and thyroxine secretion
}

\author{
D R Mann, M A Akinbami, K G Gould ${ }^{1}$ and V D Castracane ${ }^{2}$ \\ Department of Physiology, Morehouse School of Medicine, Atlanta, Georgia 30310, USA, ${ }^{1}$ Yerkes Regional Primate Research Center, Atlanta, \\ Georgia 30329, USA and ${ }^{2}$ Department of Obstetrics and Gynecology and Women's Health Research Institute of Amarillo, Texas Tech University Health \\ Sciences Center, Amarillo, Texas 79106, USA
}

(Correspondence should be addressed to D R Mann, Department of Physiology, Morehouse School of Medicine, 720 Westview Drive SW, Atlanta, Georgia 30310-1495, USA; Email:mann@msm.edu)

\begin{abstract}
Objective: Neonatal treatment of male monkeys with a gonadotropin-releasing hormone antagonist (Ant) increased the incidence of delayed puberty. Using blood samples that had been collected from monkeys with normal or delayed puberty, we assessed the potential involvement of leptin and thyroxine (T4) in sexual development.

Design and Methods: Monkeys were treated from birth until 4 months of age with vehicle, Ant or Ant/androgen and blood samples were drawn from 10 to 62 months of age.

Results: Serum leptin and total T4 concentrations declined in parallel throughout adolescence in all treatment groups. There was no transient rise in leptin before or in association with the onset of puberty. Also, leptin did not differ during the peripubertal period between animals experiencing puberty at that time versus those in which puberty was being delayed. Neonates treated with Ant either alone or with androgen replacement had higher leptin levels than controls throughout development. While leptin exhibited no significant changes during the peripubertal period, T4 values increased and declined in parallel with the peripubertal changes in hypothalamicpituitary-testicular activity.

Conclusions: These data do not support the concept that a transient rise in leptin triggers the onset of puberty in male monkeys. However, the disruption of neonatal activity of the pituitary-testicular axis alters the developmental pattern of leptin. The changes in T4 levels during the peripubertal period suggest that thyroid status may be a significant contributor to the process of sexual development in the male monkey and that peripubertal changes in secretion of this hormone may serve as an effective physiological response during a critical period of elevated energy expenditure.
\end{abstract}

European Journal of Endocrinology 146 891-898

\section{Introduction}

The achievement of a critical body weight or fat mass may be essential for supporting metabolically the process by which sexual competence is achieved (1). What remains controversial is the identity of those metabolic factors that signal the reproductive axis that body energy stores are sufficient to support this process.

Leptin and thyroxine (T4) are two hormones that may serve as a link between metabolic status and reproductive processes. The level of leptin secretion by adipose tissue is directly correlated with body fat mass
(2). Leptin regulates appetite, feeding behavior and energy utilization $(3,4)$. Leptin-deficient mice are obese and infertile $(5,6)$, conditions that are corrected with leptin administration (6). Leptin treatment induces precocious puberty in female mice $(7,8)$. Humans with a deficiency of leptin or its receptor exhibit hypogonadotropic hypogonadism $(9,10)$. In one 9-year-old girl, genetically deficient in leptin, normal pubertal development did not occur, but following 12 months of leptin treatment, gonadotropin secretion consistent with the early stages of puberty was observed (11).

Leptin has been proposed as a potential trigger for the onset of puberty in children since there is a transient 
increase in leptin levels in boys prior to or in association with pubertal activation of the gonads (12). Conversely, in another study, leptin did not change with pubertal stage in boys although it did rise in girls (13), and leptin's role in the initiation of pubertal events in humans remains controversial.

Several retrospective studies have examined the relationship between leptin secretion and sexual development in the rhesus monkey, a frequently used model for human reproduction. Two cross-sectional and one longitudinal study failed to show significant fluctuations in circulating leptin levels in association with critical peripubertal events in this species (14-16). However, nocturnal levels of leptin were recently reported to rise prior to the initiation of nocturnal, pulsatile luteinizing hormone (LH) secretion in the agonadal male monkey (17), although the significance of this finding is controversial $(18,19)$. The potential role leptin plays in sexual development in the primate remains unresolved and one of the objectives of the current study was to further examine the relationship of leptin and the timing of the onset of puberty in the male rhesus monkey.

Thyroid hormone plays a critical role in brain development and maturation and in postnatal growth and skeletal development $(20,21)$. However, the relationship between thyroid status and pubertal development remains unclear. Hypothyroidism in children is usually associated with retarded sexual maturation (22-24) although this relationship is complicated since, in some instances, hypothyroidism is associated with macro-orchidism, but without any outward signs of virilization (24). While there is general agreement that circulating levels of thyroid hormones decline throughout adolescence $(25,26)$, the relationship between thyroid status and pubertal development is not clear. Corcoran and colleagues (27) reported that there was a peripubertal nadir in circulating levels of thyroid hormones in children, although it occurred 2 years later in boys than in girls. In another crosssectional study in children in which data from boys and girls were combined, there was a transient increase in thyrotropin secretion and a resultant rise in $\mathrm{T} 4$ and tri-iodothyronine (T3) that preceded clinical pubertal changes (28). In a small longitudinal study (39 children, ranging in age from 10 to 15 years), there were significant fluctuations in both total and free T3 and T4 in association with pubertal stages of development (29). It has been suggested that these changes in thyroid hormone may play a role in the onset or evolution of puberty in children, and may serve as an effective adaptive mechanism for a period of rapid growth and increased energy requirements $(28,29)$. One of the objectives of the current longitudinal study was to examine in greater detail the relationship between thyroid status and critical peripubertal events in a non-human primate model (male rhesus monkey).
The rhesus monkey is a seasonal breeder when maintained under natural environmental conditions and the onset of puberty usually occurs during the breeding season of year 4 , otherwise it is delayed until the subsequent breeding season.

We have previously examined the importance of neonatal testosterone secretion on sexual maturation in male rhesus monkeys (30). Neonatal monkeys were treated with a gonadotropin-releasing hormone (GnRH) antagonist alone or with androgen replacement and the effect on sexual development was assessed. Fewer treated animals (44\%; combined values for the two treatment groups) than controls $(83 \%)$ reached puberty during the breeding season of their fourth year. Puberty was delayed for a year in the remaining animals. In the current study, we utilized blood samples that had been drawn from a cadre of these animals (17 that experienced puberty during year 4 , seven that exhibited delayed puberty) to examine the importance of leptin and thyroid status in the process of sexual maturation. The specific objectives were to compare developmental changes in leptin and T4 secretion between these two populations and to correlate these changes with a marker (testicular volume) of sexual development.

\section{Materials and methods}

\section{Experimental animals and blood sampling}

Experiments were performed in accordance with the principles and procedures of the NIH Guidelines for the Care and Use of Laboratory Animals. The serum samples that were used for this study were from rhesus monkeys that were born into a large social group (75 animals). The animals were maintained in an outdoor compound $(30 \times 30 \mathrm{~m})$ with an attached indoor area (temperature controlled). The subjects for this study were part of a study designed to examine the effects of neonatal testosterone on sexual and behavioral development. Animals were divided into three treatment groups: (1) vehicle control $(n=8)$, (2) GnRH antagonist (Ant, $n=8$ ) and (3) Ant and androgen (Ant/And, $n=8$ ). From birth until 4 months of age, animals were treated with vehicle or Ant (antide; Ac-D-2-Nal ${ }^{1}$-D-4-Cl-Phe ${ }^{2}$-D-3-Pal ${ }^{3}$-Nic-Lys ${ }^{6}$-I-Lys ${ }^{8}$ D-Ala ${ }^{10}-\mathrm{GnRH} ; 15 \mathrm{mg} / \mathrm{kg}$ body weight by weekly s.c. injection) or Ant/And (testosterone-trans-4,n-butylcyclohexancarboxylate; $8 \mathrm{mg} / \mathrm{kg}$ body weight by i.m. injection every other week for 6 weeks). At 4 years of age, animals were removed from the social group and were moved to a smaller outdoor compound $(15 \times$ $15 \mathrm{~m}$ ) with an attached indoor area. Blood samples were drawn from each animal without anesthesia by saphenous venipuncture every other month from 10 until 30 months of age and then monthly thereafter through 80 months of age for the assay of serum levels of leptin and T4. Serum samples were stored at 
$-70^{\circ} \mathrm{C}$ until assayed for hormones. Peripubertal changes in testicular volume in these animals have been reported previously (30). They are reported primarily to establish the timing of puberty and to show that puberty occurred at a normal age in some animals but was delayed in others. Developmental changes in leptin in the vehicle controls have also been reported previously (16). The age of onset of puberty in these animals was based on four criteria, including testicular size, serum LH and testosterone levels and whether sperm was recoverable upon electroejaculation. Of the animals used for this study, seven of eight controls, five of eight of the Ant-treated and five of eight of the Ant/And-treated animals achieved sexual maturity during the breeding season of their fourth year (4145 months of age). In the other seven animals, puberty was delayed until the subsequent breeding season.

\section{Assays}

Leptin was measured using a human leptin radioimmunoassay kit (Diagnostic Systems Laboratories, Webster, TX, USA) validated for the rhesus monkey. $\mathrm{T} 4$ levels in the serum were measured using a sensitive chemiluminescent immunoassay (Immulite; Diagnostic Products Corporation, Los Angeles, CA, USA). The intra-assay and interassay coefficients of variation for the leptin assay were 5.0 and $12.9 \%$ respectively. The interassay coefficient of variation for the T4 assay was $5.5 \%$.

\section{Statistics}

Data are presented as means \pm s.E.M. Leptin and T4 data were first partitioned into three developmental stages: juvenile (10-24 months of age), late prepubertal and peripubertal (26-50 months of age) and postpubertal (51-62 months of age). The data were then analyzed initially by two-way ANOVA (treatment $\times$ puberty achieved during year 4 vs year 5) with repeated measures over time (age) (SPSS; Advanced Statistics 6.1; SPSS, Chicago, IL, USA). When appropriate, multiple comparisons were made by Tukey's test. In cases where a significant effect of age of puberty or interaction of age of puberty and treatment on leptin levels was detected, data were further partitioned according to age of puberty and treatment and further assessed by ANOVA with repeated measures. Because we were unable to identify any significant differences in leptin levels between Ant- and Ant/And-treated animals during development, data for the two Ant-treated groups were combined in order to simplify presentation in the Figures.

During the period immediately preceding the onset of puberty during year 4 (28-38 months of age), the relationship between age, leptin, T4 and testicular volume were assessed by Pearson correlation test (two-tailed).

\section{Results}

\section{Developmental changes in leptin and $\mathrm{T} 4$ in male monkeys: effect of neonatal treatment with a GnRH antagonist}

During the juvenile period (10-24 months of age), no overall effect of treatment or age of puberty was detected on leptin concentrations, but there was a significant interaction $(P=0.03)$ of these two variables on leptin concentrations (Fig. 1, top). There were no detectable differences in leptin levels between animals that would reach puberty in year 4 versus those that would experience delayed puberty (Fig. 1, middle). Serum leptin during the juvenile period did not differ significantly across these two pubertal groups. However, within the group that reached sexual maturity during year 4 , serum leptin levels were lower $(P=$ 0.034) in controls than in Ant- and Ant/And-treated animals throughout the juvenile period (Fig. 1, bottom).

There was no detectable effect of age, treatment, age of puberty or interaction of treatment and age of puberty on T4 values during the juvenile period (data not shown).

Changes in serum leptin over the late prepubertal and peripubertal periods (26-50 months of age) were unremarkable across treatment groups (Fig. 2, top left). Before and during the time when peripubertal changes were occurring in testicular volume (Fig. 2, bottom left), leptin levels did not change significantly. Leptin concentrations did not differ between animals experiencing puberty at this time (Fig. 2, top left) versus those in which puberty was being delayed (Fig. 2, top right). However, serum leptin concentrations remained lower $(P=0.013)$ in control animals than in Ant- and Ant/And-treated animals during this period (Fig. 2, top left).

The pattern of $\mathrm{T} 4$ levels during the late prepubertal and peripubertal period was quite different between those experiencing puberty and those with delayed puberty. In contrast to leptin, there was a transient elevation of T4 levels $(P<0.003)$ during this time in animals experiencing puberty during year 4 (Fig. 2, middle left). In these animals, T4 values rose from $5.16 \pm 0.25 \mu \mathrm{g} / \mathrm{dl}$ at 41 months to a peak of $6.64 \pm$ $0.28 \mu \mathrm{g} / \mathrm{dl}$ at 43 months of age and then declined rapidly to $3.90 \pm 0.17 \mu \mathrm{g} / \mathrm{dl}$ at 46 months of age. This elevation of T4 levels appeared to occur in concert with the peripubertal increase in testicular size in these animals (Fig. 2, bottom left). Conversely, levels of T4 were more highly variable in animals with delayed puberty and there was no comparable rise in $\mathrm{T} 4$ at this time, but T4 levels did decline between 41 and 46 months of age as observed in pubertal animals (Fig. 2, middle right). There were no significant effects of treatment on T4 levels during the late prepubertal and peripubertal period, and as a result data for all 

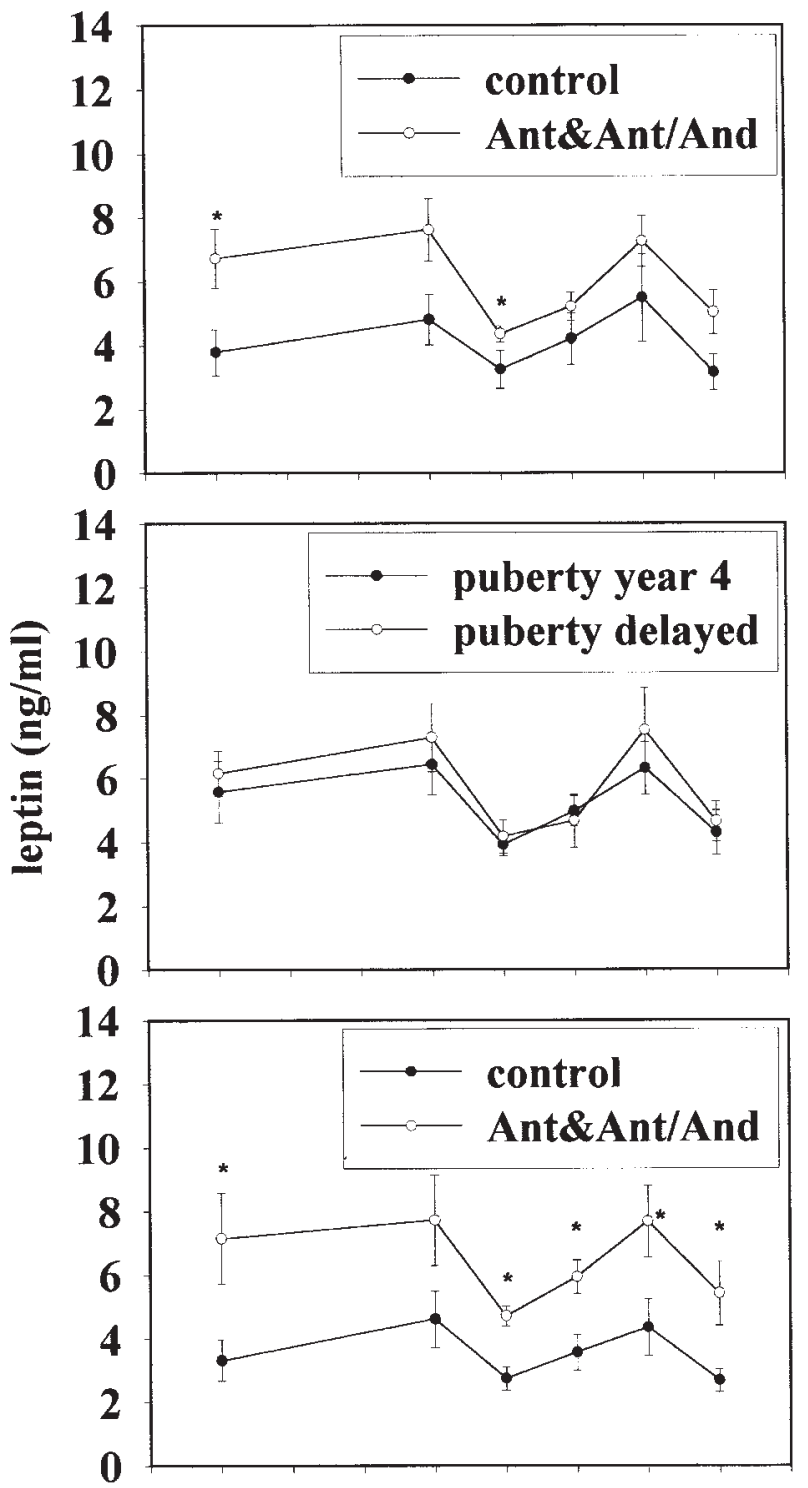

$\begin{array}{lllllllllll}8 & 10 & 12 & 14 & 16 & 18 & 20 & 22 & 24 & 26\end{array}$

\section{months of age}

Figure 1 (Top) Changes in mean serum leptin concentrations ( \pm S.E.M.) during the juvenile period in control and GnRH antagonist (Ant-) and Ant/androgen (And)-treated male monkeys. The data for Ant- and Ant/And-treated animals are combined in this panel and the bottom panel for simplification. No significant differences in leptin levels between Ant- and Ant/And-treated animals were observed during any stage of development. (Middle) Changes in mean serum leptin concentrations ( \pm S.E.M.) during the juvenile period in animals that reached puberty during year 4 and in animals with delayed puberty. (Bottom) Changes in mean serum leptin concentrations ( \pm S.E.M.) during the juvenile period in control and Ant- and Ant/And-treated male monkeys that reached puberty during year $4 .{ }^{*} P<0.05$ compared with the corresponding control value. treatment groups are combined in the middle panels of Fig. 2.

Leptin levels during the postpubertal period (50-62 months of age $)$ changed with age $(P=0.005$; Fig. 3, top). This change in postpubertal monkeys most likely resulted from a small, but significant, seasonal fluctuation in leptin that we reported previously (16). There was also an interaction $(P=0.012)$ of treatment and age of puberty on leptin levels. This latter effect (also observed in juvenile and late prepubertal and peripubertal animals) was a consequence of an effect of treatment $(P=0.05)$ on leptin in animals that reached puberty during year 4 (Fig. 3, bottom). Age of puberty did not affect leptin values during this period (Fig. 3, middle).

T4 concentrations declined $(P=0.004)$ during the postpubertal period from $5.10 \pm 0.32 \mu \mathrm{g} / \mathrm{dl}$ at 51 months to $4.40 \pm 0.25 \mu \mathrm{g} / \mathrm{dl}$ at 60 months of age (all treatment groups included). There was no effect of treatment or age of puberty on leptin levels during this period (data not shown).

\section{Correlation of leptin and T4 levels with testicular volume during the period immediately preceding the onset of puberty (28-38 months of age)}

Across treatment groups (including all animals), leptin levels were not correlated with age or testicular volume during the period immediately preceding the onset of puberty. When the data were partitioned by age of puberty only, leptin concentrations in the animals that reached puberty during year 4 were correlated $(r=$ $0.724, P=0.028$ ) with leptin levels in animals in which puberty was delayed, but not with age or testicular volumes.

Across treatment groups, T4 was negatively correlated with age $(r=-0.541, P=0.004)$, and testicular volume $(r=-0.463, P=0.015)$ during the period immediately preceding the onset of puberty. Data were not partitioned further because no major effects of age of puberty or treatment on T4 levels were detected.

\section{Discussion}

The data from this study have shown that circulating leptin levels decline throughout the juvenile period and there is no transient elevation of leptin prior to or in association with the onset of puberty in the male monkey. During the period immediately preceding the initiation of peripubertal events, leptin levels were not correlated with testicular volume or age. Moreover, there were no differences in leptin values over the normal peripubertal period between animals reaching puberty at that time compared with those in which puberty was to be delayed for another year. Of interest, 

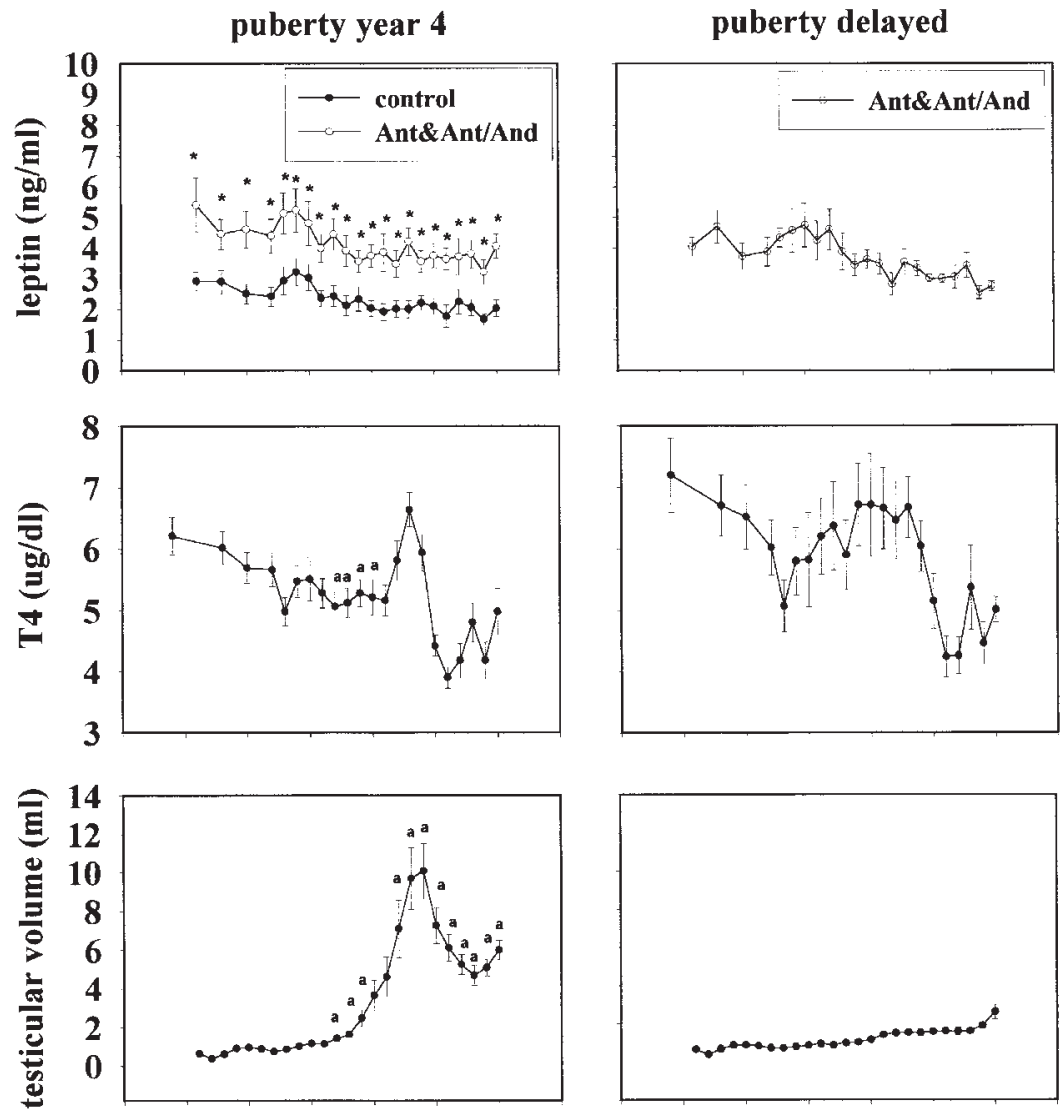

$\begin{array}{llllllllllllllll}20 & 25 & 30 & 35 & 40 & 45 & 50 & 55 & 20 & 25 & 30 & 35 & 40 & 45 & 50 & 55\end{array}$

puberty delayed
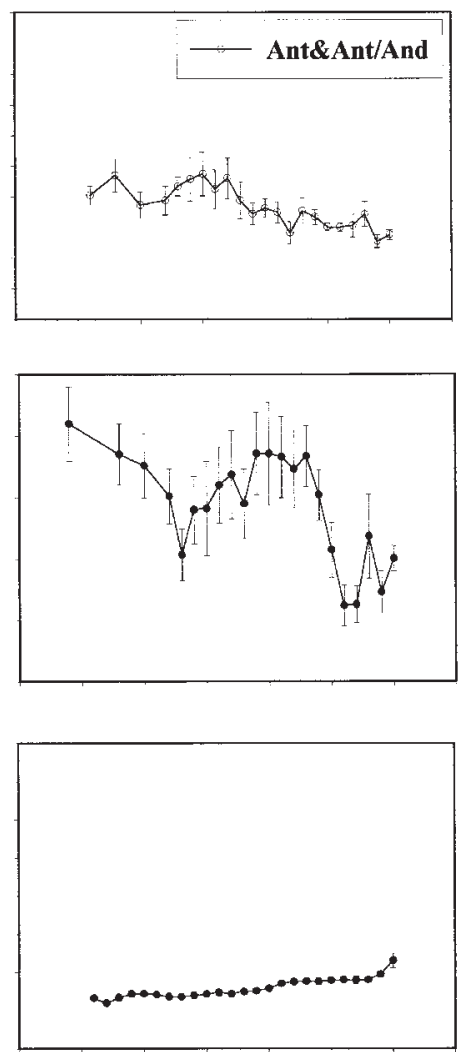

Figure 2 Panels on the left illustrate data from animals that achieved sexual maturation during year 4 of life, those panels on the right illustrate data from animals in which puberty was delayed until a year later. (Top) Changes in mean serum leptin concentrations ( \pm S.E.M.) during the peripubertal period in control and Ant- and Ant/And-treated male monkeys. The data for Ant- and Ant/Andtreated animals are combined in this panel for simplification. The top right panel does not show the data from the one control animal with delayed puberty. (Middle) Changes in mean serum thyroxine (T4) concentrations ( \pm S.E.M.) during the peripubertal period in animals that reached puberty during year 4 and in animals with delayed puberty. The T4 data for all treatment groups were combined in these panels since no significant treatment differences in T4 were detected. (Bottom) Changes in mean testicular volume ( \pm S.E.M.) during the peripubertal period in male monkeys that reached puberty during year 4 and those with delayed puberty. Data from all treatment groups are combined in the lower two panels. ${ }^{*} P<0.05$ compared with the corresponding control value. ${ }^{a} P<0.05$ compared with the value for animals with delayed puberty. however, animals treated neonatally with either Ant or Ant/And, but that experienced a normal age of onset of puberty, had elevated serum leptin levels throughout development. Thus, endocrine perturbations associated with GnRH analogue treatment during the neonatal period altered developmental changes in leptin secretion perhaps as a consequence of the effect of treatment on body composition.

The balance of the data from non-human primates (14-16 and the current study) and at least some of the data from human studies $(31,32)$ suggests that leptin plays at best a permissive rather than a dynamic role in sexual development. Leptin may serve as a metabolic gate that signals the brain that the body is capable of supporting reproductive function $(33,34)$. Not all studies in children have reported a transient increase in leptin levels before the onset of puberty as reported by Mantzoros and collaborators (12). In girls, leptin rose progressively between 5 and 15 years of age (31). In another study, leptin levels increased between Tanner's stages one and two in both boys and girls, but then diverged, continuing to rise in girls through stage 5 while declining in boys (32). It has been proposed that rising leptin levels during the growth phase may gradually sensitize GnRH-secreting neurons, eventually resulting in $\mathrm{GnRH}$ secretion and activation of the reproductive axis (35). Thus, leptin's effects on the reproductive development may occur over an extended period of time and may not be acute or abrupt (35).

Some additional data support the idea of leptin playing a permissive rather than a dynamic role in this process. Leptin concentrations were reported to be higher in patients with delayed puberty than in normal patients during prepuberty or midpuberty (36). Moreover, there was no association between activation and deactivation of the hypothalamic-pituitary-gonadal axis and leptin concentrations in patients treated with a GnRH analogue for GnRH-dependent precocious puberty (37). In partial agreement with these clinical data, we found in the current study that there were no differences in leptin values over the normal peripubertal period between monkeys experiencing puberty at that time compared with those with delayed puberty. In another human study, leptin values were higher in normal early pubertal boys than in normal prepubertal boys, but were not higher in pubertal boys with delayed puberty than in prepubertal boys with delayed puberty 

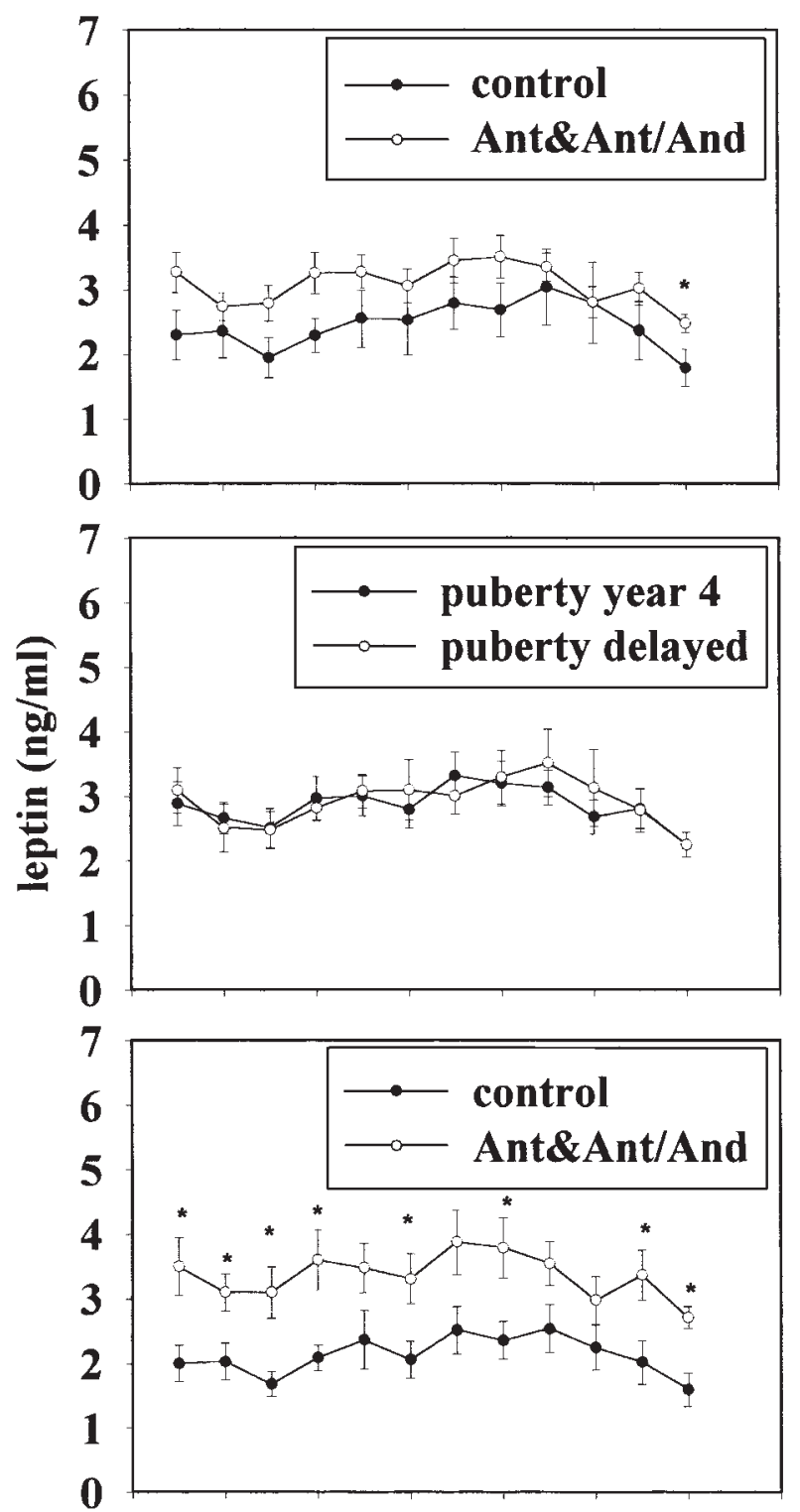

\section{$\begin{array}{llllllll}50 & 52 & 54 & 56 & 58 & 60 & 62 & 64\end{array}$ months of age}

Figure 3 Changes in mean serum leptin concentrations ( \pm S.E.M.) during the postpubertal period in control and Ant- and Ant/Andtreated male monkeys. (Top) The data for Ant- and Ant/And-treated animals are combined in this panel and the bottom panel for simplification. No significant differences in leptin levels between Ant- and Ant/And-treated animals were observed during any stage of development. (Middle) Changes in mean serum leptin concentrations ( \pm S.E.M.) during the postpubertal period in all animals that reached puberty during year 4 and in all animals with delayed puberty. (Bottom) Changes in mean serum leptin concentrations ( \pm S.E.M.) during the postpubertal period in control and Ant- and Ant/And-treated male monkeys that reached puberty during year $4 .{ }^{*} P<0.05$ compared with the corresponding control value.
(38). These data suggested that elevated levels of leptin are not essential for puberty to progress, and that puberty can occur over a wide range of leptin concentrations. Thus, leptin may not be the primary factor that initiates puberty, but lower than normal levels of leptin for a particular age in boys is associated with a delay in the onset of puberty (38). In such cases, the changing pattern in the circulating leptin receptor and, therefore, the levels of bioavailable leptin, may be important during this period of pubertal development.

In the current study, development changes in total circulating T4 levels paralleled those of leptin with some very notable exceptions. Total T4 levels, like leptin, declined throughout postnatal development. Unlike leptin, however, T4 values were unaffected by neonatal treatment with a GnRH analogue. Moreover, and perhaps more importantly, while leptin exhibited unremarkable changes during the peripubertal period, T4 levels in pubertal, but not delayed pubertal animals, showed an elevation and decline in parallel with the peripubertal changes in testicular volume. The relationship between thyroid hormones and serum leptin levels has not been fully characterized, but serum leptin levels are elevated in the hyperthyroid state (39). Moreover, in children older than 5 years of age and peripubertal subjects, T4 and leptin levels are positively correlated (40).

In several seasonal species (e.g. sheep and woodchuck), an increase in thyroid status is associated with the onset of the annual breeding season (41, 42). In the sheep, thyroid hormones are necessary for the transition from the breeding season to anestrus (43), but they are not needed to maintain anestrus once it develops or for the initiation of the next breeding season (44). The seasonal breeding cycles are considered to be analogous to the initiation of puberty, but recurrent with an annual rhythmicity. Whether the peripubertal changes in $\mathrm{T} 4$ levels in the monkey that we report here suggest thyroid involvement in initiating pubertal events or are a consequence of these events remains to be determined.

In summary, the current study does not support the concept that leptin plays a dynamic role as an initiator of puberty in the male monkey. However, the data are compatible with the concept of leptin playing a permissive role in the process of sexual development. Of increased interest, as a result of the current study, is the potential role of thyroid status as a significant contributor to this process since total circulating T4 levels increased and waned in conjunction with critical peripubertal events (e.g. increased testicular volume).

\section{Acknowledgements}

We acknowledge the invaluable assistance of Ms Terry Gimpel for performing the leptin and T4 assays. The 
Yerkes Regional Primate Research Center is fully accredited by the American Association for Accreditation of Laboratory Animal Care. This work was supported by NIH grants HD26423, RR03034 and RR00165. The $\mathrm{GnRH}$ antagonist used was synthesized at the Salk Institute under contract NO1-HD-02906 with NIH, and made available by the Contraceptive Development Branch, Center for Population Research, NICHHD, who also provided the testosterone ester.

\section{References}

1 Frisch RE. Body fat, menarche, fitness and fertility. In Adipose Tissue and Reproduction, pp 126-135. Ed. RE Frisch. Basel, Switzerland: S Karger, 1990.

2 Considine RV, Sinha MK, Heiman ML, Kriauciunas A, Stephens TW, Nyce MR et al. Serum immunoreactive-leptin concentrations in normal-weight and obese humans. New England Journal of Medicine $1996334292-295$.

3 Halaas JL, Gajiwala KS, Maffei M, Cohen SL, Chait BT, Rabinowitz $\mathrm{D}$ et al. Weight-reducing effects of the plasma protein encoded by the obese gene. Science $1995269543-546$.

4 Campfield LA, Smith FJ, Guisez Y, Devos R \& Burns B. Recombinant mouse $\mathrm{OB}$ protein: evidence for a peripheral signal linking adiposity and central networks. Science 1995269 546-549.

5 Ahima RS, Prabakaran D, Mantzoros C, Qu D, Lowell B, MaratosFlier $\mathrm{E}$ et al. Role of leptin in the neuroendocrine response to fasting. Nature $1996 \mathbf{3 8 2} 250-252$.

6 Barash IA, Cheung DK, Weigle DS, Ren H, Kabigting EB, Kuijper $\mathrm{JL}$ et al. Leptin is a metabolic signal to the reproductive system. Endocrinology $19961373144-3147$.

7 Chehab FF, Mounzih K, Lu R \& Lin ME. Early onset of reproductive function in normal mice treated with leptin. Science $1997 \mathbf{2 7 5}$ $88-90$.

8 Ahima RS, Dushay J, Flier SN, Prabakaran D \& Flier JS. Leptin accelerates the onset of puberty in normal female mice. Journal of Clinical Investigation 199799 391-395.

9 Strobel A, Issad T, Camoin L, Ozata M \& Strosberg AD. A leptin missense mutation associated with hypogonadism and morbid obesity. Nature Genetics 199818 213-215.

10 Clement K, Vaisse C, Lahlou N, Cabrol S, Pelloux V, Cassuto D et al. A mutation of the human leptin receptor gene causes obesity and pituitary dysfunction. Nature $1998392398-401$.

11 Farooqi IS, Jebb SA, Susan A, Langmack G, Lawrence E, Cheetham $\mathrm{C}$ et al. Brief report: Effects of recombinant leptin therapy in a child with congenital leptin deficiency. New England Journal of Medicine 2000341 879-884.

12 Mantzoros CS, Flier JS \& Rogol AD. A longitudinal assessment of hormonal and physical alterations during normal puberty in boys $\mathrm{V}$ : rising leptin levels may signal the onset of puberty. Journal of Clinical Endocrinology and Metabolism 199782 1066-1070.

13 Carlsson B, Ankarberg C \& Rosberg S. Serum leptin concentrations in relation to pubertal development. Archives of Disease in Childhood 199777 396-400.

14 Plant TM \& Durant AR. Circulating leptin does not appear to provide a signal for triggering the initiation of puberty in the male rhesus monkey (Macaca mulatta). Endocrinology $1997 \mathbf{1 3 8}$ 4505-4508.

15 Urbanski H \& Pau K-YF. A biphasic developmental pattern of circulating leptin in the male rhesus macaque (Macaca mulatta). Endocrinology $19981392284-2286$.

16 Mann DR, Akinbami MA, Gould KG \& Castracane VD. A longitudinal study of leptin during development in the male rhesus monkey: the effect of body composition and season on circulating leptin levels. Biology of Reproduction 200062 285-291.
17 Suter KJ, Pohl CR \& Wilson ME. Circulating concentrations of nocturnal leptin, growth hormone, and insulin-like growth factor-I increase before the onset of puberty in agonadal male monkeys: potential signals for the initiation of puberty. Journal of Clinical Endocrinology and Metabolism 200085 808-814.

18 Plant TM. Leptin, growth hormone and the onset of primate puberty. Journal of Clinical Endocrinology and Metabolism 2001 $86458-460$.

19 Suter KJ \& Wilson ME. Growth signals and puberty. Journal of Clinical Endocrinology and Metabolism 200186860.

20 Fisher DA \& Brown RS. Thyroid physiology in the perinatal period and during childhood. In Werner Ingbar's The Thyroid: A Fundamental and Clinical Text, pp 824-827. Eds LE Braverman \& RD Utiger. Philadelphia, PA: Lippincott, Williams \& Wilkins, 2000.

21 Foley TP Jr, Malvaux P \& Blizzard RM. Thyroid disease. In Wilkins, The Diagnosis and Treatment of Endocrine Disorders in Childhood and Adolescence, edn 4, pp 457-533. Eds MS Kappy, RM Blizzard \& CJ Migeon. Springfield, IL: Charles C Thomas, 1994.

22 Larsen PR \& Ingbar SR. The thyroid gland. In Textbook of Endocrinology, edn 8, pp 357-487. Eds JD Wilson \& DW Foster. Philadelphia, PA: Saunders, 1992.

23 Jannini EA, Ulisse S \& D'Armiento M. Thyroid hormone and male gonadal function. Endocrine Reviews 199516 443-459.

24 Longcope C. The male and female reproductive systems in hypothyroidism. In Werner Ingbar's The Thyroid: A Fundamental and Clinical Text, pp 824-827. Eds LE Braverman \& RD Utiger. Philadelphia, PA: Lippincott, Williams \& Wilkins, 2000.

25 Fisher DA, Sack J, Oddie TH, Pekary AE, Hershman JM, Lam RW et al. Serum T4, TBG, T3, reverse T3 and TSH concentrations in children 1 to 15 years of age. Journal of Clinical Endocrinology and Metabolism 197745 191-198.

26 Parra A, Villalpando S, Junco E, Urquieta B, Alatorre S \& GarciaBulnes G. Thyroid function during childhood and adolescence; changes in serum TSH, T4, T3, thyroxine-binding globulin, reverse T3 and free T4 and T3 concentrations. Acta Endocrinologica 198093 306-314.

27 Corcoran JM, Eastman CJ, Carter JN \& Lazzarus L. Circulating thyroid hormone levels in children. Archives of Diseases in Childhood 197752 716-720.

28 Michaud P, Foradori A, Rodriguez-Portalies JA, Arteaga E, Lopez JM $\&$ Tellez R. A prepubertal surge of thyrotropin precedes an increase in thyroxine and 3,5,3'-triiodothyronine in normal children. Journal of Clinical Endocrinology and Metabolism 199172 976-981.

29 Dunger DB, Perkins JA, Jowett TP, Edwards PR, Cox LA, Preece MA et al. A longitudinal study of total and free thyroid hormones and thyroxine binding globulin during normal puberty. Acta Endocrinologica 1990123 305-310.

30 Mann DR, Akinbami MA, Gould KG, Paul K \& Wallen K. Sexual maturation in male rhesus monkeys: importance of neonatal testosterone exposure and social rank. Journal of Endocrinology $1998156493-501$.

31 Garcia-Mayor RV, Andrade A, Rios M, Lage M, Dieguez C \& Casanueva FF. Serum leptin levels in normal children: relationship to age, gender, body mass index, pituitary-gonadal hormones, and pubertal stage. Journal of Clinical Endocrinology and Metabolism 199782 2849-2855.

32 Ahmed ML, Ong KKL, Morrell DJ, Cox L, Drayer N, Perry L et al. Longitudinal study of leptin concentrations during puberty: sex differences and relationship to changes in body composition. Journal of Clinical Endocrinology and Metabolism 199984 899-905.

33 Cunningham MJ, Clifton DK \& Steiner RA. Leptin's actions on the reproductive axis: perspectives and mechanisms. Biology of Reproduction $199960216-222$.

34 Foster DL \& Nagatani S. Physiological perspectives on leptin as a regulator of reproduction: role in timing puberty. Biology of Reproduction 199960 205-215.

35 Chehab FF. Leptin as a regulator of adipose mass and reproduction. Trends in Pharmacological Sciences 200021 309-313.

36 Giusti M, Guido R, Valenti S \& Giordano G. Serum leptin levels in males with delayed puberty during short-term pulsatile GnRH 
administration. Journal of Endocrinological Investigation 199922 $6-11$.

37 Witchel SF, Arslanian S \& Lee PA. Leptin concentrations in precocious puberty or untimely puberty with and without $\mathrm{GnRH}$ analogue therapy. Journal of Pediatric Endocrinology and Metabolism $199912839-845$

38 Gill MS, Hall CM, Tillman V \& Clayton PE. Constitutional delay in growth and puberty (CDGP) is associated with hypoleptinemia. Clinical Endocrinology 199950 721-726.

39 Sera N, Yokoyama N, Abe Y, Ide A, Imaizumi M, Tominaga T et al Thyroid hormones influence serum leptin levels in patients with Graves' disease during suppression of beta-adrenergic receptors. Thyroid $200010641-646$.

40 Asami T, Ciomarten T \& Uchiyama M. Relationship between serum leptin and thyroid hormones in children. Pediatrics International 200042 293-295.

41 Dahl GE, Evans NP, Thrun LA \& Karsch FJ. Thyroxine is permissive to seasonal transitions in reproductive neuroendocrine activity in the ewe. Biology of Reproduction 199552 690-696.
42 Concannon PW, Castracane VD \& Rawson RE. Circannual changes in free thyroxine, prolactin, testes and relative food intake in woodchucks, Marmota monax. American Journal of Physiology 1999277 R1401-R1409.

43 Karsch FJ, Dahl GE, Hachigian TM \& Thrun LA. Involvement of thyroid hormones in seasonal reproduction. Journal of Reproduction and Fertility 199549 (Suppl) 409-422.

44 Thrun LA, Dahl GE, Evans NP \& Karsch FJ. Effect of thyroidectomy on the maintenance of seasonal reproductive suppression in the ewe. Biology of Reproduction 197756 1035-1040.

Received 24 September 2001

Accepted 12 March 2002 